\title{
Synthesis and Characterization of Photonic Polyesters Containing Azo Chromophore in the Side Chain
}

\author{
Ling Qiu, Jiaxin Zhang, Jianfeng ZhaI, and Yuquan Shen \\ Institute of Photographic Chemistry, Chinese Academy of Sciences, Beijing 100101, China
}

(Received November 10, 1995)

\begin{abstract}
A series of polyesters with covalently attached push-pull azobenzene groups have been synthesized and characterized. Some important properties for photonic applications such as thermal stability, solubility, and film forming behavior are investigated and discussed.

KEY WORDS Polyester / Push-Pull Azobenzene Group / Azo Chromophore / NLO Materials / Photonic/
\end{abstract}

The studies of side chain polymers have received much attention. For photonic applications, side chain polymers have several advantages comparing with guest-host systems or main chain polymers: a high chromophore concentration can be incorporated into a polymer system without crystallization and phase separation; the glass transition temperature $\left(T_{\mathrm{g}}\right)$ of such system is substantially higher than that of a guest-host system containing the same concentration of chromophore molecules; chromophore in the side chain polymer is not restricted severely as in main chain polymer, so electric poling is still reasonably effective.

The synthesis of a polyester with DR-1 as side chain was reported by Chen and his coworkers. ${ }^{1}$ In the present work, we have synthesized a series of polyesters with covalently attached different push-pull azobenzene groups. The chemical structures of the polymers are shown in Scheme 3. Different from the conventional method, these polymers were synthesized by firstly forming colorless polyester and then by further reaction of the colorless polyester and diazonium salts as shown in Schemes 2 and 3. The polymers prepared in our work have chromophore contents of $29-74 \%$ in weight, much higher than that in guest-host polymers. These polymers are soluble in many organic solvents, and can be made into thin films by spin-coating. We will also report other characterizations of the polymers.

\section{EXPERIMENTAL}

\section{Terephthalaldehyde (1)}

It was prepared according to a literature procedure. ${ }^{2}$ At first, tetrabromo- $p$-xylene was synthesized by bromination of $p$-xylene, and then the tetrabromide was hydrolyzed in concentrated sulfuric acid to form 1. $\mathrm{mp}$ $115-116^{\circ} \mathrm{C}$ (literature: $115-116^{\circ} \mathrm{C}$ ).

\section{p-Phenylenediacrylic Acid (2)}

The mixture of $1(6.0 \mathrm{~g}, 0.044 \mathrm{~mol})$, anhydrous sodium acetate $(12.0 \mathrm{~g}, 0.146 \mathrm{~mol})$ and redistilled acetic anhydride $(10.8 \mathrm{~g}, 0.106 \mathrm{~mol})$ were reacted at $150^{\circ} \mathrm{C}$ for $2 \mathrm{~h}$, and then another $10.8 \mathrm{~g}$ of acetic anhydride was added. The reaction mixture was heated for $15 \mathrm{~h}$, dissolved in sodium carbonate solution and filtered. To the filtrate was added $120 \mathrm{ml}$ of $2 \mathrm{M}$ hydrochloric acid. The resulting product was washed with water, air-dried and then extracted with hot acetic acid to remove monoacrylic acid. It gave compound 2 in $41 \%$ yield. $\mathrm{mp}>360^{\circ} \mathrm{C}$. IR $v_{\mathrm{O}-\mathrm{H}} 3200-$ $2400 \mathrm{~cm}^{-1}(\mathrm{br}), v_{\mathrm{C}=\mathrm{O}} 1675 \mathrm{~cm}^{-1}$. MS: $218\left(\mathrm{M}^{+}\right), 173$ $\left(\mathrm{M}^{+}-\mathrm{COOH}\right), 128\left(\mathrm{M}^{+}-2 \mathrm{COOH}\right)$.

\section{p-Phenylenediacryloyl Chloride (3)}

$2(6.0 \mathrm{~g}, 0.028 \mathrm{~mol})$ and anhydrous potassium carbonate $(12.0 \mathrm{~g}, 0.086 \mathrm{~mol})$ were refluxed in $40 \mathrm{ml}$ of redistilled thionyl chloride for $16 \mathrm{~h}$. Excess thionyl chloride was removed by distillation. The residue was extracted with hot petroleum ether, and allowed to cool. The precipitated crystals were recrystallized from petroleum ether to give $2.2 \mathrm{~g}$ (yield: $31 \%$ ) of 3 . IR: $v_{\mathrm{C}=\mathrm{o}} 1743 \mathrm{~cm}^{-1}$. MS: $254\left(\mathrm{M}^{+}\right), 184\left(\mathrm{M}^{+}-2 \mathrm{Cl}\right), 128\left(\mathrm{M}^{+}-2 \mathrm{COCl}\right)$.

\section{Terephathloyl Chloride (4)}

This was prepared by a procedre similar to the above, giving 4 in $40 \%$ yield. $\mathrm{mp} 79-81^{\circ} \mathrm{C}$ (literature ${ }^{3}$ : $83-$ $\left.84^{\circ} \mathrm{C}\right)$.

\section{1-(4-Aminophenyl)-2,2'-dicyano Ethene (5)}

$2 \mathrm{ml}$ of piperidine which was dissolved in acetic acid was added dropwise to a solution of $1.1 \mathrm{~g}(0.016 \mathrm{~mol})$ of malononitrile and $2.0 \mathrm{~g}(0.016 \mathrm{~mol})$ of 4-aminobenzaldehyde in $40 \mathrm{ml}$ of ethanol. The reaction mixture was stirred and refluxed for $6 \mathrm{~h}$, cooled to room temperature. The resulting solid product was recrystallized from ethanol-water and dried, yielding $2.1 \mathrm{~g}(75 \%)$ of yellow compound 5. IR: $v_{\mathrm{N}-\mathrm{H}} 3448,3356 \mathrm{~cm}^{-1}, v_{\mathrm{C} \equiv \mathrm{N}} 2205 \mathrm{~cm}^{-1}$. MS: 169 $\left(\mathrm{M}^{+}\right) .{ }^{1} \mathrm{H}$ NMR $\left(\mathrm{CD}_{3} \mathrm{COCD}_{3}\right): \delta 3.33(\mathrm{~s}, 2 \mathrm{H}), 6.84(\mathrm{~d}$, $J=3.2 \mathrm{~Hz}, 2 \mathrm{H}), 7.86(\mathrm{~d}, J=3.2 \mathrm{~Hz}, 2 \mathrm{H}), 7.87(\mathrm{~s}, 1 \mathrm{H})$.

\section{4-Aminophenyl 2-Hydroxyethyl Sulfide (6)}

Sodium $(2.1 \mathrm{~g}, 0.090 \mathrm{~mol})$ was dissolved in $18 \mathrm{ml}$ of absolute ethanol with stirring under nitrogen, $11 \mathrm{~g}$ $(0.088 \mathrm{~mol})$ of 4 -aminothiophenol was added in small portions, and then $7.1 \mathrm{~g}(0.088 \mathrm{~mol})$ of 2-chloroethanol was added. The resulting mixture was heated at reflux for $2 \mathrm{~h}$ and filtered, and the filtrate was concentrated. The residue was dissolved in dichloromethane. The solution was washed with water, $5 \%$ sodium bicarbonate, and again with water, dried over sodium sulfate. The solvent was evaporated, and the residue was purified by column chromatography on silica gel with benzene/ 
ethanol as eluent to afford $7.4 \mathrm{~g}$ of 6 . Yield: $50 \%$. MS: 169 $\left(\mathrm{M}^{+}\right), 138\left(\mathrm{M}^{+}-\mathrm{CH}_{2} \mathrm{OH}\right), 124\left(\mathrm{M}^{+}-\mathrm{CH}_{2} \mathrm{CH}_{2} \mathrm{OH}\right)$.

\section{4-Acetamidophenyl 2-Acetoxyethyl Sulfide (7)}

A solution containing $7.4 \mathrm{~g}(0.44 \mathrm{~mol})$ of $6,110 \mathrm{~g}$ $(0.11 \mathrm{~mol})$ of redistilled acetic anhydride, and $88 \mathrm{~g}$ $(0.11 \mathrm{~mol})$ of anhydrous pyridine was refluxed for $6 \mathrm{~h}$. The solution was poured onto ice, and the precipitate was collected, washed with water, $5 \%$ hydrochloric acid, and again with water. The product was recrystallized from methanol-water to give $8.0 \mathrm{~g}(72 \%)$ of 7 . MS: 253 $\left(\mathrm{M}^{+}\right), 194\left(\mathrm{M}^{+}-\mathrm{OCOCH}_{3}\right), 151\left(\mathrm{M}^{+}-\mathrm{OCOCH}_{3}-\right.$ $\mathrm{COCH}_{3}$ ).

\section{4-Aminophenyl 2-Hydroxyethyl Sulfone (8)}

A mixture of $8.0 \mathrm{~g}(0.032 \mathrm{~mol})$ of 7 and $50 \mathrm{ml}$ of acetic acid was heated to reflux with stirring. Hydrogen peroxide $(9.5 \mathrm{~g}, 30 \%)$ was added in small portions, and the resulting mixture was refluxed for $5 \mathrm{~h}$. The reaction mixture was concentrated, and the residue was dissolved in dichloromethane. The solvent was distilled off. The residue was heated at reflux with stirring for $20 \mathrm{~h}$ in 50 $\mathrm{ml}$ of $50 \%$ aqueous ethanol containing $10 \%$ sodium hydroxide. The resulting solution was extracted with ether. The extract was dried over magnesium sulfate, and the solvent was removed. The residue was purified by column chromatography to afford $1.5 \mathrm{~g}(24 \%)$ of 8 . IR: $v_{\mathrm{N}-\mathrm{H}} 3461,3357 \mathrm{~cm}^{-1}, v_{\mathrm{OH}} 3239 \mathrm{~cm}^{-1}, v_{\mathrm{SO}_{2}} 1306$, $1131 \mathrm{~cm}^{-1}$, MS: $201\left(\mathrm{M}^{+}\right), 156\left(\mathrm{M}^{+}-\mathrm{CH}_{2} \mathrm{CH}_{2} \mathrm{OH}\right), 140$ $\left(\mathrm{M}^{+}-\mathrm{CH}_{2} \mathrm{CH}_{2} \mathrm{OH}-\mathrm{NH}_{2}\right):{ }^{1} \mathrm{H} \mathrm{NMR}\left(\mathrm{CD}_{3} \mathrm{COCD}_{3}\right): \delta$ $3.10(\mathrm{t}, J=8.0,2 \mathrm{H}), 3.35(\mathrm{~m}, 2 \mathrm{H}), 4.30(\mathrm{t}, J=5.0,1 \mathrm{H})$, $6.10(\mathrm{~s}, 2 \mathrm{H}), 6.60(\mathrm{~d}, J=8.5,2 \mathrm{H}), 7.40(\mathrm{~d}, J=8.5,2 \mathrm{H})$.

Polymer 1. $3(2.13 \mathrm{~g}, 8.36 \mathrm{mmol})$ and $N$-phenyldiethanolamine $(1.54 \mathrm{~g}, 8.44 \mathrm{mmol})$ were dissolved in $30 \mathrm{ml}$ of dry 1,2-dichloroethane under nitrogen atmosphere, stirred at reflux for $4 \mathrm{~h}$. Then, the mixture was poured into methanol to precipitate the polymer. The polymer was redissolved and reprecipitated, dried at $40-50^{\circ} \mathrm{C}$ under vacuum for $24 \mathrm{~h}$, yielding polymer 1: $3.02 \mathrm{~g}, 98.1 \%$. Softening point: $80^{\circ} \mathrm{C}$.

Polymer 2. 4(1.04 g, $5.12 \mathrm{mmol})$ and $N$-phenyldiethanolamine $(0.937 \mathrm{~g}, 5.17 \mathrm{mmol})$ were treated by a similar procedure as the synthesis of polymer 1 to afford $1.58 \mathrm{~g}$ $(99.2 \%)$ of polymer 2 . Softening point: $71^{\circ} \mathrm{C}$.

Polymer 3. 4-Nitroaniline $(0.30 \mathrm{~g}, 4.3 \mathrm{mmol})$ was dissolved in $0.45 \mathrm{ml}$ of hydrochloric acid and $1.5 \mathrm{ml}$ water, then poured onto $3 \mathrm{~g}$ of ice with stirring. Sodium nitrite $(0.15 \mathrm{~g}, 4.3 \mathrm{mmol})$ was added at once. The mixture was reacted at $0-5^{\circ} \mathrm{C}$ for 30 minutes and filtered. To the filtrate was added $0.4 \mathrm{~g}$ of sodium fluoroborate, which was dissolved in a small amount of water. The resulting precipitate was washed with water, dried in the air and $0.34 \mathrm{~g}$ of diazonium salt was obtained. Then the diazonium salt was added to a solution of polymer 1 $(0.400 \mathrm{~g})$ in $40 \mathrm{ml}$ of acetone containing $2.0 \mathrm{~g}$ of anhydrous sodium acetate. The reaction mixture was reacted at $20-30^{\circ} \mathrm{C}$ with stirring for $10 \mathrm{~h}$, then poured into water to precipitate the dark red solid, which was washed with water, dried at $40-50^{\circ} \mathrm{C}$ under vacuum for $24 \mathrm{~h}$, yielding $0.532 \mathrm{~g}$ of polymer 3. Anal. Calcd for $\left[\mathrm{C}_{22} \mathrm{H}_{20} \mathrm{NO}_{4}\left(\mathrm{C}_{6} \mathrm{H}_{4} \mathrm{~N}_{3} \mathrm{O}_{2}\right) \times 84 \%\right]_{n}: \mathrm{C}, 66.49 \% ; \mathrm{H}$, $4.79 \%$; N, $10.09 \%$. Found: C, $65.06 \%$; H, 4.76\%; N, 1028
$9.80 \%$.

Polymer 4. 2,4-Dinitroaniline $(0.26 \mathrm{~g}, 1.4 \mathrm{mmol})$ was dissolved in $5 \mathrm{ml}$ of acetic acid, and $0.10 \mathrm{~g}(1.4 \mathrm{mmol})$ of sodium nitrite was added at once. The mixture was stirred for 40 minutes, then was added to a solution of polymer $1(0.402 \mathrm{~g})$ in $40 \mathrm{ml}$ of acetone containing sodium acetate $(2 \mathrm{~g})$. The solution was stirred for $10 \mathrm{~h}$, then treated as described above, yielding $0.616 \mathrm{~g}$ of polymer 4. Anal. Calcd for $\left[\mathrm{C}_{28} \mathrm{H}_{23} \mathrm{~N}_{5} \mathrm{O}_{8}\right]_{n}: \mathrm{C}, 60.32 \% ; \mathrm{H}, 4.13 \% ; \mathrm{N}$, $12.56 \%$. Found: C, $59.42 \%$; H, $4.19 \%$; N, $12.94 \%$.

Polymer 5. $5(0.24 \mathrm{~g}, 1.42 \mathrm{mmol})$ was diazotizated in acetic acid with $0.10 \mathrm{~g}(1.45 \mathrm{mmol})$ of sodium nitrite, then added to a acetone solution of polymer $1(0.290 \mathrm{~g})$ containing $2 \mathrm{~g}$ of anhydrous sodium acetate, stirred for $10 \mathrm{~h}$, treated as described above, yielding $0.546 \mathrm{~g}$ of polymer 5.

Polymer 6. $8(0.116 \mathrm{~g}, 0.578 \mathrm{mmol})$ was diazotizated with sodium nitrite $(0.0400 \mathrm{~g}, 0.579 \mathrm{mmol})$ and then was added to a solution of polymer $1(0.187 \mathrm{~g})$ containing $1 \mathrm{~g}$ of anhydrous sodium acetate. The mixture was stirred for $10 \mathrm{~h}$, treated as described above, yielding $0.228 \mathrm{~g}$ of polymer 6.

Polymer 7. This was prepared by a similar procedure as the synthesis of polymer $\mathbf{3}$ except that polymer $\mathbf{2}$ was used instead of polymer 1 in the coupling reaction.

Polymer 8. This was prepared by a similar procedure as the synthesis of polymer $\mathbf{4}$ except that polymer $\mathbf{2}$ was used instead of polymer $\mathbf{1}$ in the coupling reaction.

Polymer 9. This was prepared by a similar procedure as the synthesis of polymer $\mathbf{5}$ except that polymer $\mathbf{2}$ was used instead of polymer $\mathbf{1}$ in the coupling reaction.

Infrared spectra were recorded using a Perkin-Elmer 983G IR spectrometer, with film samples cast on sodium chloride crystal disk or dry samples incorporated in potassium bromide disk. Ultra-violet and visible spectra were obtained on a Hitachi $340 \mathrm{UV} /$ vis spectrophotometer. Molecular weight measurements were taken employing a Waters gel-permeation chromatographic instrument. Thermal analyses were performed using Perkin-Elmer TGA-7 systems with a heating rate of $20^{\circ} \mathrm{C}$ $\min ^{-1}$ and BJOSW Model 4-1 thermal analyzer with a heating rate of $10^{\circ} \mathrm{C} \mathrm{min}{ }^{-1}$ under nitrogen atmosphere.

\section{RESULTS AND DISCUSSION}

Monomers 3, 4, 5, and 8 were prepared by reaction routes described in Scheme 1. To prepare 3, we choose a four-step reaction route, in which $\mathbf{2}$ is firstly prepared. $\mathbf{2}$ is insoluble in many organic solvents and the pure compound was obtained by dissolving the reaction product in a sodium carbonate solution, reprecipitating it by adding hydrochloric acid and then extracting it with hot acetic acid to remove monoacrylic acid. 5 can be easily synthesized by the reaction of 4-aminobenzaldehyde and malononitrile with piperidine as catalyst. Monomer $\mathbf{8}$ is prepared by a four-step reaction route starting from 4-aminothiophenol.

Polyesters containing azobenzene chromophore in the side chain are usually prepared by polymerization of monomers containing the chromophore. ${ }^{1,4-7}$ Here, we propose a new route, in which colorless polymer is firstly synthesized and then the azobenzene chromophore is introduced into the polymer side chain by diazo coupling 

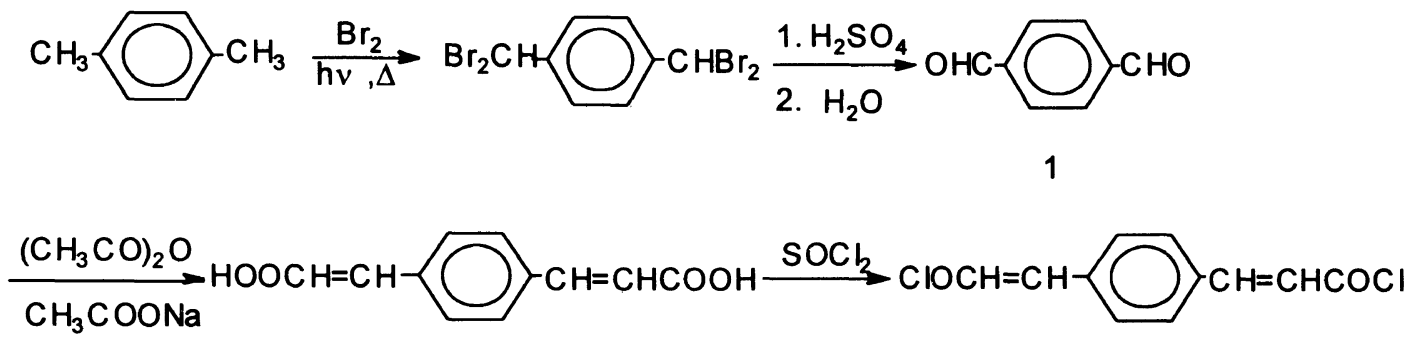

2

3<smiles>O=C(O)c1ccc(C(=O)CCCCCC(=O)c2ccc(C(=O)Cl)cc2)cc1</smiles>

4<smiles>N#CC(C#N)=Cc1ccc(N)cc1</smiles>

5

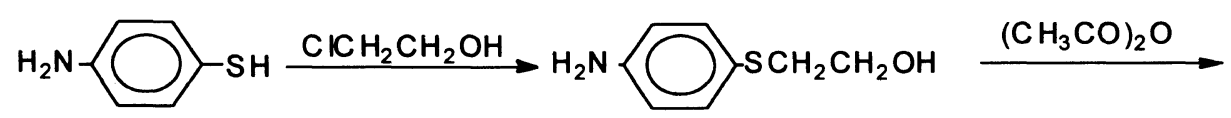

6

$\mathrm{CH}_{3} \mathrm{CONH} \bigcirc-\mathrm{SCH}_{2} \mathrm{CH}_{2} \mathrm{OCOCH}_{3} \stackrel{\mathrm{H}_{2} \mathrm{O}_{2}}{\longrightarrow} \mathrm{CH}_{3} \mathrm{CONH} \longrightarrow-\mathrm{SO}_{2} \mathrm{CH}_{2} \mathrm{CH}_{2} \mathrm{OCOCH}_{3}$

7<smiles>Nc1ccc(S(=O)(=O)CCO)cc1</smiles>

8

Scheme 1.
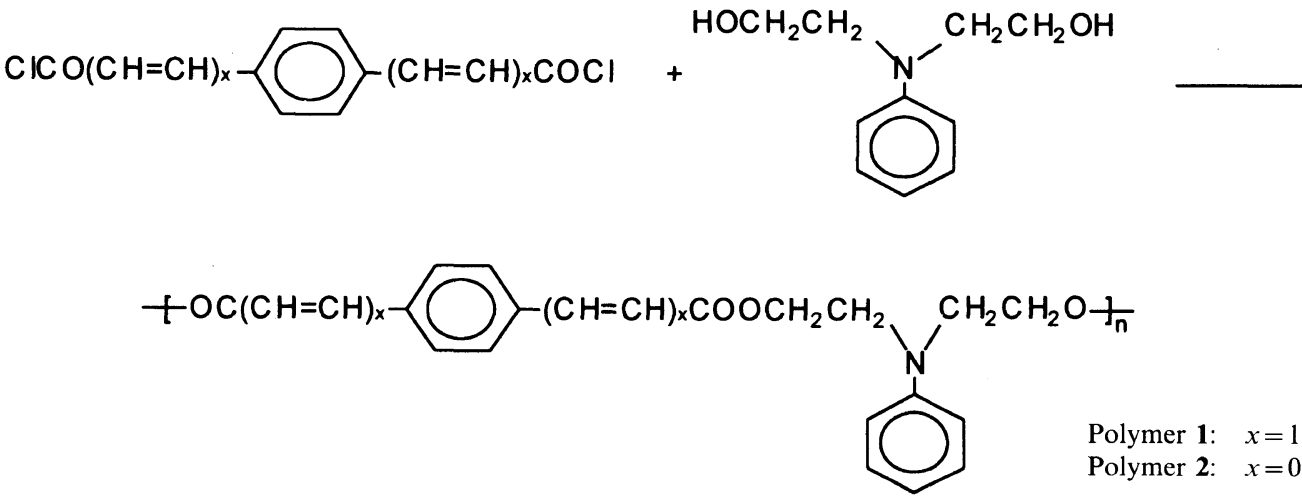

Scheme 2.

reaction (see Schemes 2 and 3).

Polymers $\mathbf{1}$ and $\mathbf{2}$ are synthesized by polymerization of a diol and a dicarbonyl chloride in a high yield. The weight-average molecular weights of them are 20000 and 17000 , respectively.
The polymers containing azo chromophore are formed by diazo coupling reaction. Generally, the diazo coupling reaction is carried out in aqueous solution. But this is not possible in our case because polymers 1 and $\mathbf{2}$ are insoluble in water. We modified the procedure by making 


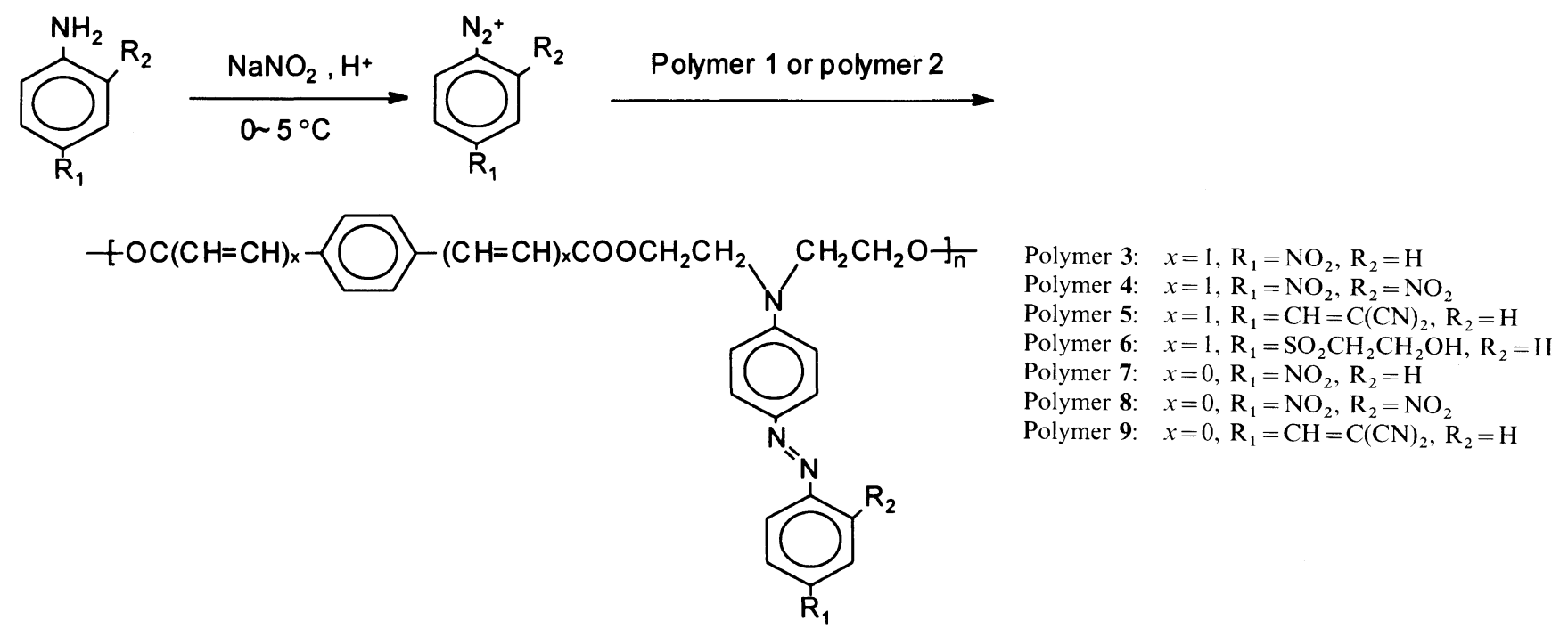

Scheme 3.

Table I. Chromophore content in polymers

\begin{tabular}{crr}
\hline & \multicolumn{2}{c}{ Chromophore content } \\
\cline { 2 - 3 } Polymer & $\mathrm{mol} \%$ & $\mathrm{wt} \%$ \\
\hline $\mathbf{1}$ & 0 & 0 \\
$\mathbf{2}$ & 0 & 0 \\
$\mathbf{3}$ & 84 & 54 \\
$\mathbf{4}$ & 100 & 67 \\
$\mathbf{5}$ & 98 & 65 \\
$\mathbf{6}$ & 43 & 29 \\
$\mathbf{7}$ & 67 & 48 \\
$\mathbf{8}$ & 100 & 74 \\
$\mathbf{9}$ & 72 & 53 \\
\hline
\end{tabular}

diazonium salts precipitated from water with a large anion, such as $\mathrm{BF}_{4}^{-}$, and then coupling the diazonium salts with polymers $\mathbf{1}$ or $\mathbf{2}$ in organic solvent (see the syntheses of polymers $\mathbf{3}$ and 7 ) or by directly carrying out the diazo coupling reaction in a suitable organic solvent (see the syntheses of polymers $4 \mathbf{6 , 8}$, and $\mathbf{9}$ ).

Chromophore contents in the polymers are estimated according to the weight difference between polymers after and before the coupling reaction and are listed in Table I. Elemental analysis data for polymer 3 and polymer 4 (see Experimental section) indicate that this method is available. It can be noted that not all the mole content of the chromophore in these polymers are $100 \%$, and the polymers with vinylene groups in the main chain or with stronger electron-withdrawing groups $\left(R_{1}\right.$ and $\left.R_{2}\right)$ in the side chain have higher chromophore contents. Enhancing of the chromophore content in the case of introducing the vinylene group may be ascribed to steric effect in the coupling reaction, because the vinylene group in the main chain can leave more space between the two nearby aniline groups. When $R_{1}$ and $R_{2}$ are more electron-withdrawing, the diazonium group will be more easily coupled to the polymer backbone, so the chromophore content is higher. The chromophore contents in weight in these polymers are in the range of $29-74 \%$, much higher than that in guest-host system.

Table II gives some properties of the seven polyesters prepared. It is worthwhile to note that the measured 1030
Table II. Polymer properties

\begin{tabular}{|c|c|c|c|c|}
\hline \multirow{2}{*}{ Plymer } & \multirow{2}{*}{$\begin{array}{l}\text { Molecular weight }{ }^{\mathrm{a}} \\
\text { (weight-average) }\end{array}$} & \multirow{2}{*}{$\frac{T_{\mathrm{g}}}{{ }^{\circ} \mathrm{C}}$} & \multirow{2}{*}{$\begin{array}{l}\text { Decomposition } \\
\text { temp } /{ }^{\circ} \mathrm{C}\end{array}$} & \multirow{2}{*}{$\frac{\lambda_{\max }^{\mathrm{b}}}{\mathrm{nm}}$} \\
\hline & & & & \\
\hline 3 & 7200 & 148 & 307 & 470 \\
\hline 4 & 15000 & 150 & 276 & 509 \\
\hline 5 & 22000 & 120 & 254 & 502 \\
\hline 6 & 24000 & 111 & 242 & 441 \\
\hline 7 & & 135 & 317 & 466 \\
\hline 8 & 9100 & 146 & 270 & 496 \\
\hline 9 & 19000 & 113 & 280 & 492 \\
\hline
\end{tabular}

values of molecular weight in Table II have only limited meaning since a fixed solvent of tetrahydrofuran (THF) was used for their determination and a polymer portion with higher molecular weights might be filtered off before determination because of their poor solubility. So the real molecular weights of the polymers should be larger than those listed in the table.

As expected, the color of the polymers are from reddish orange to purplish red as the electron-withdrawing ability of $R_{1}$ and $R_{2}$ increased. The difference in $\lambda_{\max }$ of the polymers is due to the electron-withdrawing ability of $R_{1}$ and $R_{2}$. The electron withdrawing ability of $R_{1}$ and $R_{2}$ in the polymers (with the same polymer backbone) is in the order of polymer $4>5>3>6$ and $8>9>7$, and the $\lambda_{\text {max }}$ values for these polymers decrease in the same order. The polymer backbone also has some influence on $\lambda_{\max } . \lambda_{\max }$ values of polymers with vinylene group in the main chain are slightly larger than polymers without vinylene group in the main chain.

The thermal properties of these polymers have been studied by DTA and TGA. Figure 1 shows the DTA traces of the polymers, from which $T_{\mathrm{g}}$ values can be read out and are listed in Table II. The exotherms in the figure are associated with the degradation processes, because it shows weight loss at the same temperature in TGA. The decomposition temperatures of the polymers are listed in Table II. For each polymer, there are 1-3 degradation processes before $450^{\circ} \mathrm{C}$ and the sharp exothermic step may be the elimination of the azo group, 


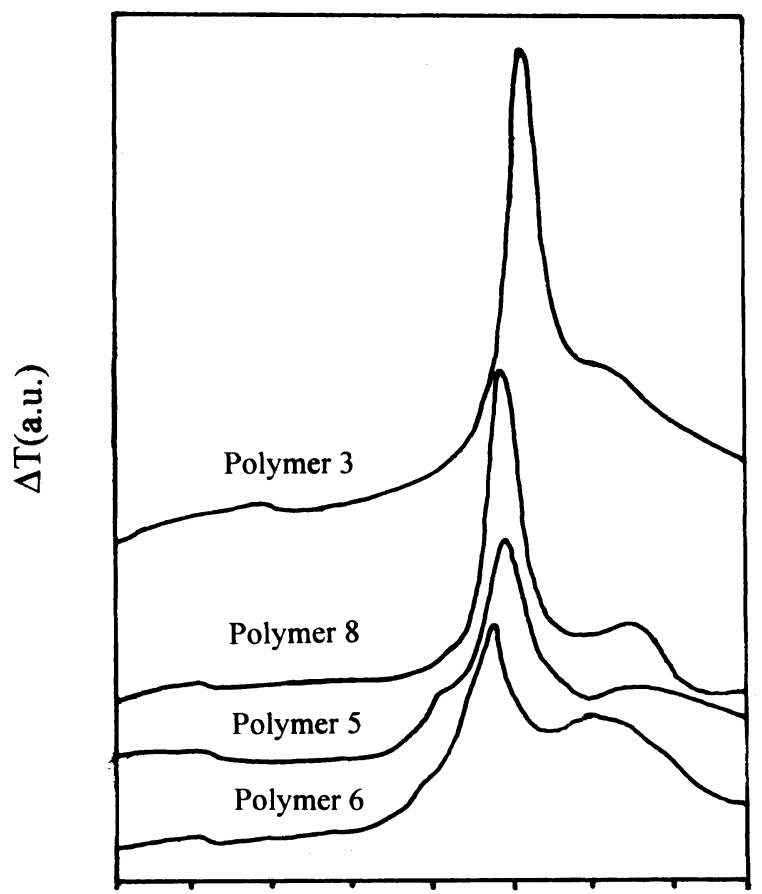

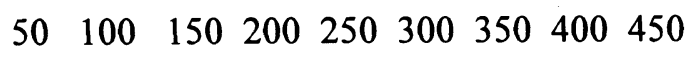

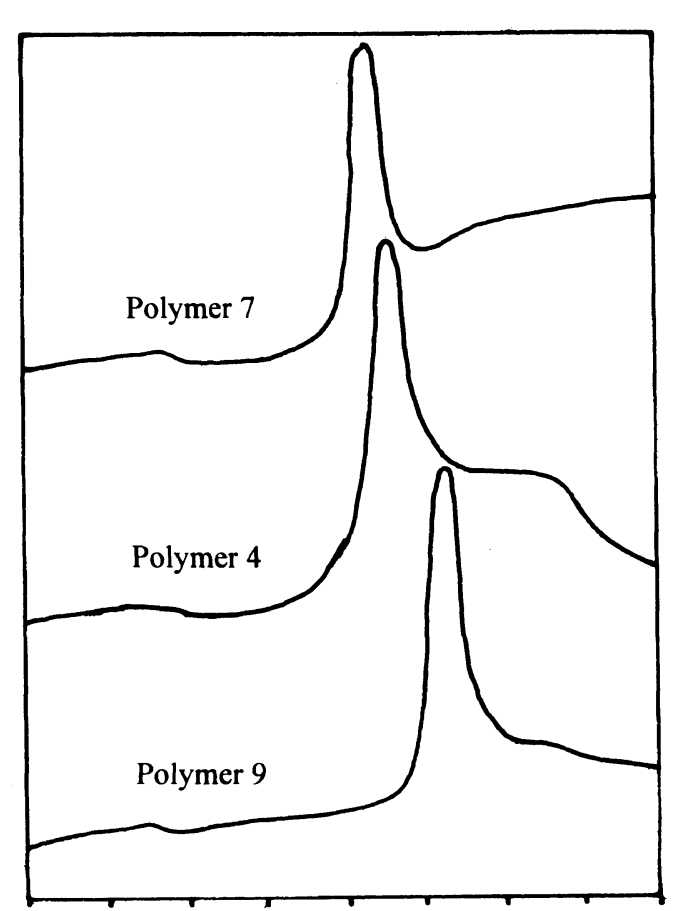

100150200250300350400450

Temperature $\left({ }^{\circ} \mathrm{C}\right)$

Figure 1. DTA traces of the polymers.

possibly as molecular nitrogen. Such a process has been reported in the thermal degradation of some azo polymers. ${ }^{8}$ It can be noted that the temperatures at the sharp exotherms are quite near for the polymers with the same $R_{1}$ and $R_{2}$ but different polymer backbone, which gives support to the suggestion that the sharp stages in the thermal decomposition of the polymers are due to the elimination of the azo group. In polymers $\mathbf{3}, \mathbf{4}, \mathbf{7}, \mathbf{8}$, and $\mathbf{9}$, the first degradation steps are the sharp exotheric steps, namely the elimination of the azo group. But in polymers 5 or $\mathbf{6}$, there is a small exotherm before the sharp one and it is corresponding to the first weight loss steps in the TGA (weight loss for polymers $\mathbf{5}$ and $\mathbf{6}$ are $2 \%$ and $3 \%$, respectively). It is probably due to the reaction of $-\mathrm{CH}=\mathrm{C}(\mathrm{CN})_{2}$ or $-\mathrm{SO}_{2} \mathrm{CH}_{2} \mathrm{CH}_{2} \mathrm{OH}$ with the vinylene group in the polymer backbone, because the small degradation before the sharp exotherm does not occur in polymer 9 , which has $-\mathrm{CH}=\mathrm{C}(\mathrm{CN})_{2}$ group but no vinylene group in the main chain. Substituents on the azo benzene ring can also influence the decomposition temperature of the polymers. Among these polymers, polymer 3 , where $\mathrm{R}_{1}=-\mathrm{NO}_{2}$ and $\mathrm{R}_{2}=\mathrm{H}$, has the highest decomposition temperature, while polymer $\mathbf{6}$, where $\mathrm{R}_{1}=-\mathrm{SO}_{2} \mathrm{CH}_{2} \mathrm{CH}_{2} \mathrm{OH}$ and $\mathrm{R}_{2}=\mathrm{H}$, has the lowest. We note that the decomposition temperatures of polymers 4 and $\mathbf{8}\left(\mathrm{R}_{1}, \mathrm{R}_{2}=-\mathrm{NO}_{2}\right)$ are quite lower than that of polymers 3 and $7\left(R_{1}=-N_{2}, R_{2}=H\right)$, which is probably due to the interaction between the $o$-nitro group and azo bond in such $o$-nitroazobenzene polymers. The decomposition temperatures of polymers $\mathbf{3}$ and $\mathbf{7}$, or $\mathbf{8}$ and $\mathbf{9}$, which have the same substituents $\left(R_{1}\right.$ and $\left.R_{2}\right)$ but different polymer backbone, are quite close, indicating that the vinylene groups in the polymer backbone have only little effect on the decomposition temperature if it does not react with the substituents in the polymers.

Infrared spectra of the polymers are shown in Figure 2. The absorptions due to nitro groups can be observed around $1508-1525$ and $1336-1337 \mathrm{~cm}^{-1}$. For polymers 5 and 9, the cyano absorptions appear at 2226 and 2225 $\mathrm{cm}^{-1}$. The absorption band due to $-\mathrm{SO}_{2}-$ in polymer 6 is around $1319 \mathrm{~cm}^{-1}$. The carbonyl absorption in polymers 7, 8, and 9 are $1711-1716 \mathrm{~cm}^{-1}$, and for polymers 3,4 , and 5 , they are around $1705-1707 \mathrm{~cm}^{-1}$ due to conjugation with the vinylene group. For all these polymers, the absorptions due to the azo group appear at around $1600 \mathrm{~cm}^{-1}$, which are overlapped by aromatic bands.

The solubility characteristics of the polymers are shown in Table III. The polymers have good solubility in organic solvents, except for polymer 7. Polymer 3 is soluble or very soluble in chloroform, hexanone, pyridine, DMF and formic acid; polymers $\mathbf{4}$ and 8 in hexanone, formic acid, $N, N$-dimethyl formamide (DMF), THF, dimethyl sulfoxide (DMSO), and pyridine; polymers 5 and 9 in chloroform, dichloromethane, dioxane, hexanone, DMF, pyridine, and formic acid; polymer 6 in chloroform, dichloromethane, hexanone, formic acid, DMF, THF, and DMSO. But polymer 7 is insoluble in many organic solvents. It is only slightly soluble in hexanone, DMF and pyridine. From the solution in which the polymers are soluble or very soluble, thin films can be obtained by spin coating.

In conclusion, seven polyesters with different push-pull azobenzene chromophores as side chain have been synthesized and some properties for photonic applications including molecular weight, glass transition temperature, decomposition temperature, absorption wavelength and solubility were determined and discussed on 


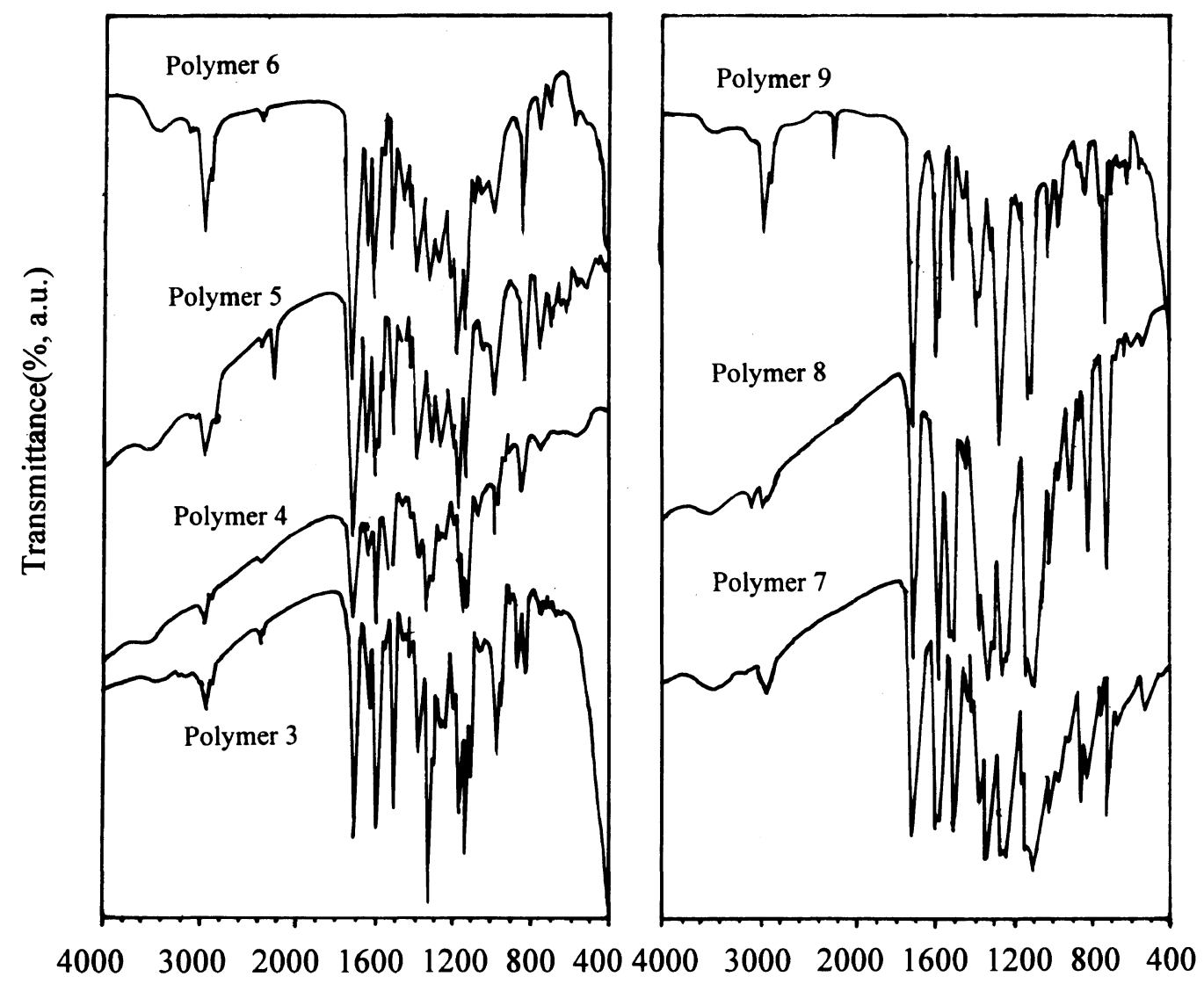

Wave number $\left(\mathrm{cm}^{-1}\right)$

Figure 2. IR spectra of the polymers.

Table III. Polymer solubility ${ }^{\mathrm{a}}$

\begin{tabular}{|c|c|c|c|c|c|c|c|}
\hline \multirow{2}{*}{ Solvent } & \multicolumn{7}{|c|}{ Polymer } \\
\hline & 3 & 4 & 5 & 6 & 7 & 8 & 9 \\
\hline Benzene & 0 & + & 0 & 0 & 0 & 0 & 0 \\
\hline Chloroform & ++ & 0 & +++ & ++ & 0 & + & +++ \\
\hline Dichloromethane & + & + & ++ & ++ & 0 & 0 & ++ \\
\hline THF & + & ++ & +++ & ++ & 0 & ++ & +++ \\
\hline Hexanone & ++ & ++ & $++t$ & +++ & + & ++ & ++ \\
\hline Dioxane & + & + & ++ & + & 0 & + & ++ \\
\hline Acetone & 0 & + & + & 0 & 0 & + & + \\
\hline Ethyl acetate & 0 & + & 0 & 0 & 0 & + & + \\
\hline DMF & ++ & ++ & ++ & +++ & + & ++ & ++ \\
\hline DMSO & + & ++ & + & +++ & 0 & ++ & + \\
\hline Pyridine & ++ & +++ & ++ & +++ & + & ++ & ++ \\
\hline Formic acid & +++ & ++ & +++ & ++ & 0 & ++ & +++ \\
\hline
\end{tabular}

${ }^{\mathrm{a}} 0$, insoluble; + , slightly soluble; ++ , soluble; +++ , very soluble.

the basis of the relationship between chemical structure and properties.

Acknowledgment. This research was carried out under financial supports from the National 863 Program Committee and the National Natural Science Foundation of China.

\section{REFERENCES}

1. M. Chen, L. Yu, L. R. Dalton, Y. Shi, and W. H. Steler, Macromolecules, 24, 5421 (1991).

2. J. M. Snell and A. Weissberger, "Organic Syntheses," Collective Volume 3, E. C. Horning, Editor-in-Chief, John Wiley \& Sons,
Inc., New York, N.Y., 1955. p. 788.

3. K. W. Rosenmund, Ber., 54, 2888 (1921).

4. H. Katz, K. Singer, J. Sohn, C. Dirk, L. King, and H. Gordon, J. Am. Chem. Soc., 109, 6561 (1987).

5. K. Singer, W. Holland, M. Kuzyk, G. Wolk, H. Katz, M. Schilling, and P. Cahill, "Proceedings of the Society of Photo-optical Instrumentation Engineers (SPIE), Vol. 1143." The International Society for Optical Engineers, Washington, D.C., 1989 , p. 223.

6. S. Matsumoto, K. Kubodera, T. Kurihara, and T. Kaino, Appl. Phys. Lett., 51, 1 (1987).

7. Y. Shuto, M. Amano, and T. Kaino, Jpn. J. Appl. Phys., 30, 320 (1991).

8. H. C. Bach and W. B. Black, in "Advance in Chemistry Series," No. 91, The American Chemical Society, Washington, D. C., 1969 , p. 679. 